\title{
A STUDY ON THE INFLUENCE OF TRANSPORTATION INFRASTRUCTURE CONSTRUCTION ON REGIONAL ECONOMIC DEVELOPMENT
}

\author{
Nagoya University $\bigcirc$ Chunlu Liu ${ }^{1}$ \\ Nagoya University Yoshito Itoh ${ }^{2}$
}

\begin{abstract}
In recent years, it has been widely recognized that the transportation infrastructure construction is highly correlated with the economic development, especially in developing countries. The quality and quantity of transportation infrastructure systems have a direct bearing on economic growth. Bottlenecks in the provision of transportation infrastructure facilities can severely retard the growth in all economic sectors of a country or a region. Therefore, the developing countries are facing the challenges of updating and expanding their infrastructure facilities so that the economic growth will not be retarded from the lack of infrastructure construction. This research focuses on modeling the relationships among economic development in terms of the growth rate of the gross domestic product and the transportation infrastructure construction in terms of the growth rates of lengths of various transportation modes using the statistical data reported from government agencies. These relationships are helpful for making decisions on transportation infrastructure construction and investment policies both within the transportation modes at the regional level and among regions of a country for a specific transportation mode.
\end{abstract}

KEYWORDS: economic growth, estimation model, sustainable development, transportation infrastructure construction, transportation modes

\section{INTRODUCTION}

In the previous research, the importance of transportation infrastructure construction for the regional economic performances has been extensively discussed, especially for the developing countries and regions [1-4]. In the past development history of some developed countries, the patterns of infrastructure development are also closely correlated with the development phases of economies such as in Japan [5] and USA [6]. The quality and quantity of transportation infrastructure systems have a direct bearing on economic growth. Bottlenecks in the provision of transportation infrastructure facilities can severely retard the growth in all economic sectors of a country or a region. Numerous authors have included the infrastructure as an additional argument of the production function to declare that the public infrastructure can be taken as an input factor in the production process that contributes to output independently. The common and widely used methodology is the ordinary least squares (OLS) [711], which is also named the single-equation regression model or linear regression model. The two-stage least squares (TSLS) regression model was also used to simultaneously estimate the relationships between the transportation

\footnotetext{
${ }^{1}$ Assistant Professor, Department of Civil Engineering, Nagoya University, $+052-789-2736$

${ }^{2}$ Professor, Center for Integrated Research in Science and Engineering, Nagoya University, +052-789-2737
} 
infrastructure construction and the economic development from two directions [12-14].

The developing countries such as China are facing the challenges of updating and expanding their infrastructure facilities so that the economic growth will not be retarded due to the lack of the infrastructure. For around two decades, infrastructure issues have risen to the forefront of the policy agenda of the central and local governments in China. Because the transportation infrastructure systems consist of networks, relieving bottlenecks at certain points of the systems can produce very high returns on the economic growth. One striking example is that of China's intercity transportation system with its links to the supply of raw materials, coal and electricity as mentioned in a World Bank report [3]. Therefore, a research effort is needed to study in detail the economic effects of various transportation modes in China so that more ideal decisions can be made to allocate the capital investment either among transportation modes of a specific region or among regions for a specific transportation mode.

This research focuses on modeling the relationships among economic development in terms of the growth rate of the gross domestic product (GDP) and transportation infrastructure construction in terms of the growth rates of the lengths of various transportation modes using the statistical data reported by the government agencies. These relationships are helpful for making decisions on the transportation infrastructure construction and investment policies both within the transportation modes at the regional level and among regions of a country for a specific transportation mode. The rest of this paper is organized as follows. In the following section, a conceptual framework is described to show how the transportation infrastructure construction can improve the economic capacity. The third section discusses the construction of four main transportation modes in Guangdong province in detail from the viewpoints of investment, supply and demand of each transportation mode. In section 4 , an estimation model is established to include various transportation modes in addition to the traditional productive arguments such as the labor, investment and exports and applied for Guangdong province to identify a specific formulation using the historical data from the statistical yearbooks. Finally, the fifth section concludes this study.

\section{ROLES OF TRANSPORTATION INFRASTRUCTURE CONSTRUCTION IN ECONOMIC DEVELOPMENT}

The relationship between the transportation infrastructure construction and the economic growth has been a controversial issue for many years. The key point is that either the infrastructure construction causes the economic development or the economic development leads infrastructure investment. However, in recent years, greater recognition has been given to the role of infrastructure investment in economic development, following the findings of many studies that infrastructure variables are positive and significantly correlated with the GDP growth [10]. Infrastructure's linkages to an economy are multiple and complex because it affects production and consumption directly, creates many positive and negative externalities, and involves large flows of expenditure. While a transportation infrastructure project is undertaken, various economic impacts may be generated [11]. Figure 1 represents a conceptual framework to describe the influence of infrastructure construction on GDP via improving its various endogenous dominant parameters including the capital, labor, resource, facility, and technology, and so on in the following of this section $[15,16]$. 


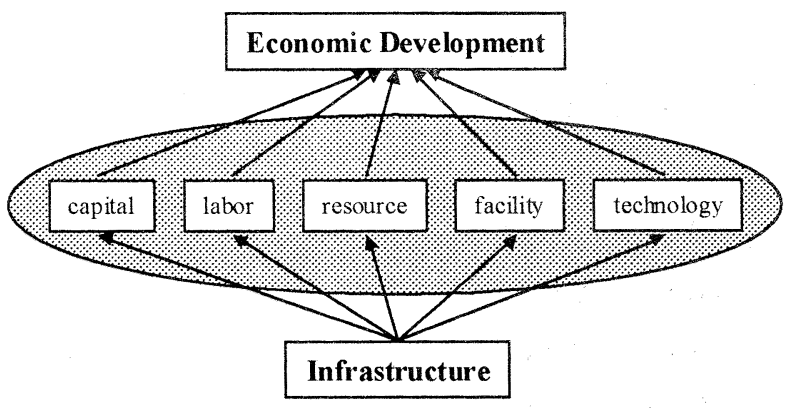

Figure 1: Influence Flow of Infrastructure Construction on Economic Development

First, better transportation infrastructure may increase a region's capacity to attract investment from both home and abroad. Actually, the latter has proved an important stimulus to the economy and foreign trade in the Guangdong province since the 1980s. Because of its proximity to Hong Kong and Macao, Guangdong province has been achieving the rapid rural industrialization under the financial support from the abroad, and various manufacturing factories financially supported by foreign investors have been established.

Secondly, with the improvement of transportation infrastructure, the availability of employment for a locality will increase and the time consumption of users will be reduced generally. The infrastructure user costs will be decreased in the long term because of the improvement of infrastructures.

Third, the improved infrastructure facilitates the formation and integration of the domestic market and hence leads the long-term effect of expanding the productive capacity of a region by increasing resources and enhancing the productivity of existing resources. Transportation shortage has also adverse affects on raw materials and energy supply, which is also vital to economic growth. In such a circumstance, improvement in the provision of transportation services should have a large marginal effect on output. As an important component of resources, the values of the land of a region will increase with the construction of new transportation infrastructure.

Forth, the impact of infrastructure development on economic growth is usually more significant when a bottleneck exists in the economy as a result of an under developed infrastructure. Although there has been rapid infrastructure development in recent years in China, it has not been able to adequately meet the economic growth.

Fifth, as the transportation infrastructure is improved in the developing regions, it will become possible to raise the productive technologies timely by either transferring from the industrial regions or developing in that area. The technology is an internal motive force of the economic development.

\section{TRANSPORTATION INFRASTRUCTURE CONSTRUCTION IN GUANGDONG}

\subsection{TRANSPORTATION INFRASTRUCTURE CONSTRUCTION}

As the economy in China grows and population mobility increases, the pattern of investment on various transportation infrastructure modes also changes. Figure 2 shows the percentages of capital investment in the four main transportation modes in China, including railways, highways, waterways, and airways.

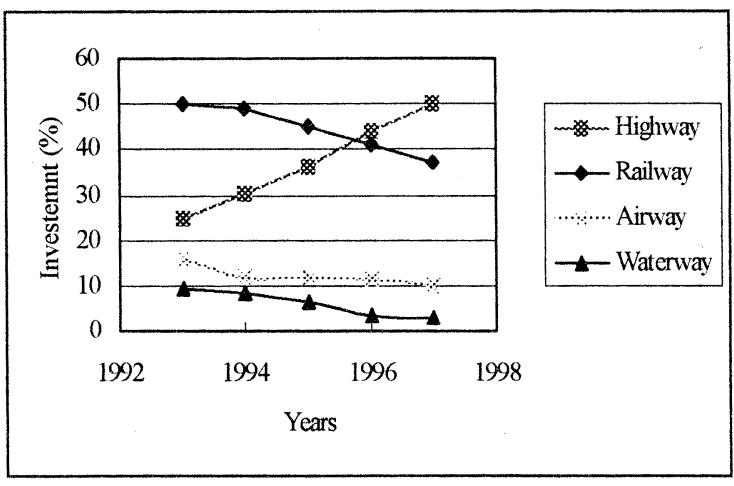

Figure 2: Change of Investment in Various Transportation Modes in China 
In the past 5 years, the share of transportation investment in highway construction continued to increase from $24.9 \%$ in 1993 to $49.9 \%$ in 1997 . It is the year 1996 that the construction investment on highways surpassed it on railway. From this figure, it can be predicted that the highway construction will be the dominant investment area for improving the transportation capacity in China. The shares in the other three transportation modes decreased year after year, among which the yearly investment increase rate in airways is bigger than the rates in the other two. These figures may indicate that the priority of development of the transportation system has shifted from the traditional means of transportation such as railways and waterways to highways and airways.

In Guangdong province, the components of transportation infrastructure construction investment in the railways, highways, waterways, and airways are $14.4 \%, 47.7 \%, 24.4 \%$, and $13.5 \%$ respectively in 1992 . These percent rates changed to $11.7 \%$, $56.5 \%, 8.5 \%$, and $23.3 \%$ in 1996 . As a result, the length of civil aviation routes increased by as much as five times from 1989 to 1996 in Guangdong province as shown in Figure 3. In this figure, the length index represents a relative rate by indicating the route length of each transportation mode as 100 in 1989. During this period, the length of railways, highways and waterways increased by $89.5 \%$, $66.5 \%$ and $0.1 \%$ respectively.

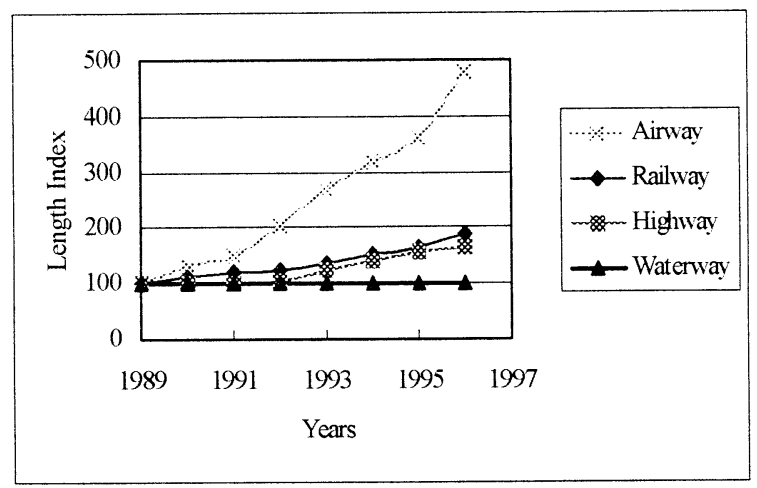

Figure 3: Change of Lengths of Various Transportation Modes in Guangdong Province

\subsection{DEMANDS OF VARIOUS TRANSPORTATION INFRASTRUCTURE}

Figures 4 and 5 show the changes indices of passengers and freights in various transportation modes in Guangdong province from 1989 and 1996. The values of passengers and freights in various transportation modes in 1989 are designated to be 100 in Figures 4 and 5 respectively.

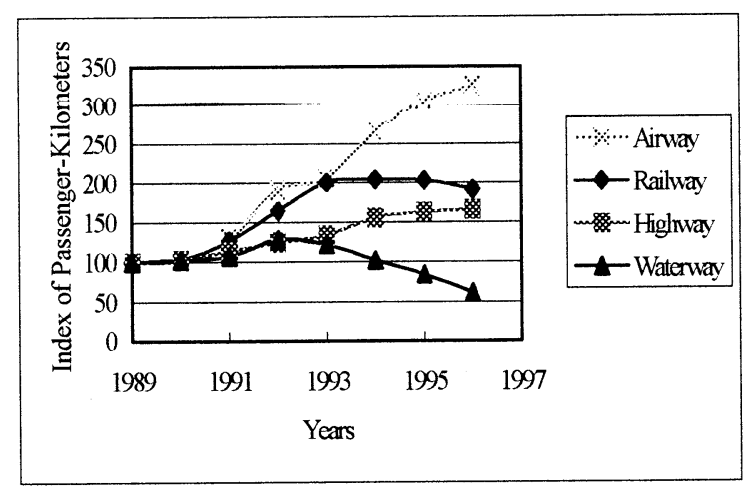

Figure 4: Change of Passengers of Various Transportation Modes in Guangdong Province

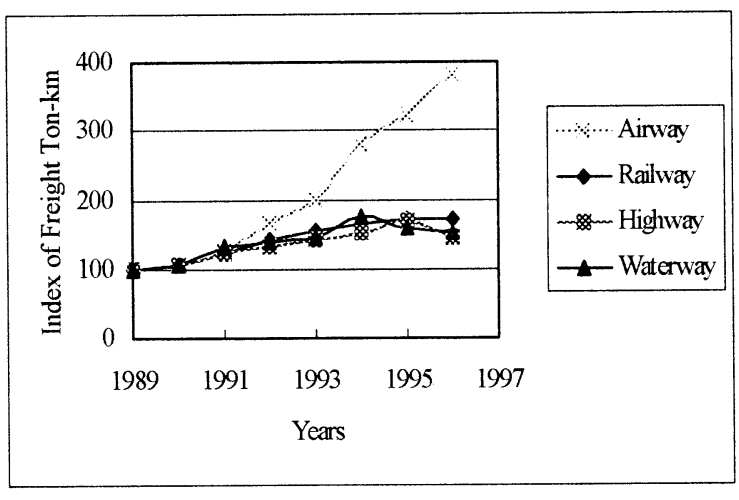

Figure 5: Change of Freights of Various Transportation Modes in Guangdong Province

In general, a high increasing freight intensity and a low increasing passenger intensity happened as $113.6 \%$ and $86.3 \%$ respectively between 1989 and 1996. The air transportation increased much faster than the other three ways in both the freight traffic turnover volume and passenger traffic. As shown in Figure 4 , in terms of the passenger traffic, the passenger-kilometers of water transportation 
decreased about 50\% from 1992 to 1996 due to the relatively slow transportation speed of the waterway. However, the turnover volume of freight traffic by means of the waterway increased about $50 \%$ within this period. Increasing speeds of the freight and passengers are near in railways and highways in 1996. It should be noticed that the railway and waterway are still the highly dominant modes to transport freights although they took effects of less than 30\% in transporting passengers in 1996. It can be predicted that the highways and airways will become more and more important transportation manners for the movement of passengers as the economy in Guangdong province continues to grow. The high demands in these transportation modes are accompanied with the relatively high percentages of construction investments in the previous years as presented in Figure 2 and will lead high effects on the economic development.

\section{INFLUENCE OF INFRASTRUCTURE CONSTRUCTION ON ECONOMIC GROWTH}

\subsection{ESTIMATION MODEL}

The effects of transportation construction in various transportation modes on economic development are analyzed in the framework of a production-function model using panel data of Guangdong province from 1989 to $1996[10,17]$. The economic performance is measured as the growth rate of GDP in each year. Various transportation modes are considered as productive parameters in addition to the traditional input parameters such as the labor, capital, and export parameters, and the estimation equation is specified as follows:

$$
\begin{aligned}
\triangle \mathrm{GDP}= & \alpha_{0}+\alpha_{\mathrm{L}} \Delta \mathrm{L}+\alpha_{\mathrm{I}} \triangle \mathrm{I}+\alpha_{\mathrm{E}} \Delta \mathrm{E}+\alpha_{\mathrm{R}} \Delta \mathrm{R} \\
& +\alpha_{\mathrm{H}} \Delta \mathrm{H}+\alpha_{\mathrm{W}} \Delta \mathrm{W}+\alpha_{\mathrm{A}} \triangle \mathrm{A}
\end{aligned}
$$

where, the symbol $\triangle$ GDP represents the annual growth rate of the gross domestic product, and the symbols $\triangle \mathrm{L}, \triangle \mathrm{I}, \triangle \mathrm{E}, \triangle \mathrm{R}, \triangle \mathrm{H}, \triangle \mathrm{W}$, and $\triangle \mathrm{A}$ are the growth rates of the labor input, investment, export, railway, highway, waterway, and airway, respectively. The coefficients $\alpha_{\mathrm{L}}, \alpha_{\mathrm{I}}, \alpha_{\mathrm{E}}, \alpha_{\mathrm{R}}, \alpha$ ${ }_{\mathrm{H}}, \alpha_{\mathrm{W}}$, and $\alpha_{\mathrm{A}}$ represent their elasticity of output, among which the symbols $\alpha_{\mathrm{R}}, \alpha_{\mathrm{H}}, \alpha_{\mathrm{W}}$, and $\alpha_{\mathrm{A}}$ indicate the direction and the marginal impact on economic performance due to the increase of a unit of growth rates in the railway, highway, waterway, and airway transportation modes, respectively. According to Eq. (1), the coefficient $\alpha_{0}$ is finally determined using the mean values of these eight items and the other seven coefficients that can be obtained from the regression analysis. Due to the limitation of statistical data, the analysis is limited to linear mean-value functions at present, but the procedure of the regression analysis can be easily updated once more data are available.

Changes in infrastructure construction are generally related to changes in the gross domestic product. This is why a number of studies have attempted to utilize production functions to estimate the contribution of infrastructure to economic development. However, the distribution of central government funds and foreign funds and the decisions about where to invest has had a significant impact on the regional capacity to deliver infrastructure services to local economies in China. This is because the central government and increasing foreign funds available provide the large grants for the regional development of infrastructure. Therefore, the physical stock of infrastructure rather than the investment data should be used to analyze the impact of infrastructure development on economic growth. This is because the physical stock is the outcome of earlier investment by both local and central governments as well as by foreign investors, and thus its changes are unlikely to be directly related to the different economic growth 
rates among regions. In this study, the growth rates of lengths, not the investments, of various transportation modes are taken as the indicators that may affect the economic growth. The labors and exports are the total values in all economic sectors of a region, and the investment represents the total investment in both the capital construction and the innovation in all economic sectors.

\subsection{PANEL DATA AND ESTIMATION PROCEDURE}

In the present research, the empirical analysis uses the data for 1989 to 1996 obtained from the various issues of the Guangdong Statistical Yearbooks published [17]. Data on the growth rates of the gross domestic product, labor input, investment, export and various transportation modes are shown in Table 1. The mean and standard deviation of each variable are also shown in this table. The estimation method of ordinary least squares is applied to determine the equation presented in the above subsection. Results from the multiple linear regression analysis are also presented in Table 1. From these results, the mean annual growth rate of the gross domestic product with the growth rates of the labor input, investment, export and four transportation modes is given by

$$
\begin{gathered}
\triangle \mathrm{GDP}=13.87+0.03 \triangle \mathrm{L}-0.04 \triangle \mathrm{I}+0.12 \triangle \mathrm{E} \\
-0.45 \triangle \mathrm{R}+0.98 \triangle \mathrm{H}+0.21 \triangle \mathrm{A}
\end{gathered}
$$

The influence of the growth rate of the waterway is near to zero due to its little change in the length in the previous years. The coefficient for railways is negative because the growth rates of GDP are relatively small while the growth rates of railways are high in several years such as in 1990 and 1996. This may be understood from the fact that the investment on the railway construction needs a huge amount, but its profit can not be created at the same year. In the case of highway, the peaks of growth rates appeared in the same year of 1993 and followed in 1994. The importance of infrastructure development for economic performance is clearly borne out in the above empirical results. These results indicate that a 1 percentage of improvement in the provision of highway and airway would lead to increases in output by 0.98 per cent and 0.21 percent respectively. These results are consistent with the earlier speculation that there is a high need in both the highway and the airway.

Table 1 OLS Estimation of Regression Equation in Guangdong Province

\begin{tabular}{|c|c|c|c|c|c|c|c|c|}
\hline Year & $\triangle \mathrm{GDP}$ & $\triangle \mathrm{L}$ & $\triangle \mathrm{I}$ & $\triangle \mathrm{E}$ & $\triangle \mathrm{R}$ & $\triangle \mathrm{H}$ & $\triangle \mathrm{W}$ & $\triangle \mathrm{A}$ \\
\hline 1990 & 12.86 & 3.00 & 20.28 & 19.40 & 14.10 & 1.58 & 0.59 & 32.16 \\
\hline 1991 & 21.44 & 4.53 & 23.90 & 29.62 & 6.14 & 1.16 & 0 & 14.35 \\
\hline 1992 & 29.27 & 3.31 & 25.26 & 34.72 & 4.32 & 1.04 & 0 & 37.27 \\
\hline 1993 & 40.22 & 1.98 & 37.66 & 46.57 & 9.75 & 20.88 & -0.45 & 29.46 \\
\hline 1994 & 31.61 & 1.73 & 47.49 & 73.87 & 10.29 & 12.08 & 0 & 19.05 \\
\hline 1995 & 26.95 & 1.66 & 47.41 & 20.43 & 7.88 & 11.68 & 0 & 13.41 \\
\hline 1996 & 13.54 & 2.54 & 40.59 & 4.87 & 14.83 & 5.99 & 0 & 32.04 \\
\hline Mean $(\triangle)$ & 25.13 & 2.68 & 34.65 & 32.78 & 9.62 & 7.78 & 0.02 & 25.39 \\
\hline Standard Deviation & 9.17 & 0.95 & 10.57 & 20.71 & 3.60 & 6.93 & 0.28 & 8.89 \\
\hline Coefficient $(\alpha)$ & 13.87 & 0.03 & -0.04 & 0.12 & -0.45 & 0.98 & 0 & 0.21 \\
\hline
\end{tabular}




\section{CONCLUSIONS AND DISCUSSIONS}

This research aims to provide a review of the construction of various transportation infrastructure modes and their effects on the economic growth in the south area of China, Guangdong province. Based on this research the following conclusions can be stated and the further work will be discussed afterwards:

(1) A conceptual framework is presented to reflect the effects of transportation infrastructure construction onto the gross domestic product via improving its endogenous variables.

(2) By comparing the development trends of investment, demand and supply in various transportation modes, it is made clear that highways and airways will take more effects in transporting the freights and passengers in the future of Guangdong province although the railway and waterway took the key roles just a few years ago.

(3) An estimation model is presented to quantify the effects and needs of various transportation modes in Guangdong province from the economic perception. It was found that a 1 percentage of improvement in the provision of highways and airways would lead to the increases in GDP by 0.98 per cent and 0.21 percent respectively. However, the railways and waterways did not show positive and statistically significant effects on economic growth in Guangdong province.

The estimation approach in the influence of infrastructure construction onto the economic development is a promising research and development trend [13]. However, a great deal of further research effort remains to be carried out in the future as follows:
(1) It should be noticed that due to the inadequacy of data at present, there is a need to improve this model by including more data and to improve the accuracy of findings such as the coefficients although the present linear regression model can be adopted to briefly reflect the relationship and development trend.

(2) With the collection of more consistent data, the simultaneous equations under the two-stage least squares will be developed to estimate the mutual relationships of transportation construction and economic development from both directions.

(3) In order to determine a rational numerical equation representing the relationships between the growth rate of GDP and input variables, further studies are needed for identifying the endogenous variables of GDP and incorporating them into a comprehensive formulation. On the other hand, the variables used in this research should be further specified such as by taking the paved roads and employed rate into consideration of the highway and labor respectively.

(4) Comparative analyses will be carried out with the estimation results in some previous research focusing on other countries or regions [3, 7-14]. It would be also useful to extend the analysis to permit a cross-country comparison of the infrastructure construction and the economic development.

(5) The transportation infrastructure construction also plays an important role in the protection of the natural environment, and the improvement of the inhabitant income and living standard, and the formulations for such issues related to the local and global sustainable development need further studies. 


\section{ACKNOWLEDGEMENT}

A part of the work in this paper was supported by the Japan Society for the Promotion of Science (JSPS). However, the opinions stated in this paper are those of the authors alone and do not reflect any official position of JSPS.

\section{REFERENCES}

[1] Hewings, G. J. D., Schindler, G. R., and Isailevich, P. R., "Infrastructure and economic development: airport capacity in Chicago region, 2001-18," Journal of Infrastructure Systems, ASCE, 3(3), 1997, pp. 96-102.

[2] Kessides, C., and Ingram, G. K., "Infrastructure's impact on development: lessons from WRD 1994," Journal of Infrastructure Systems, ASCE, 1(1), 1995, pp. 16-32.

[3] World Development Report Infrastructure Development. Oxford University Press, New York.

[4] Wright, D. W., "Infrastructure planning and sustainable development," Journal of Urban Planning and Development, ASCE, 122(4), 1996, pp. 111-117.

[5] Yoshida, T., "Infrastructure Development and Economic Growth in Japan and South Korea," Workshop Proceedings on ASEAN Infrastructure Planning \& Management, 1998, pp.88-94.

[6] Aschauer, D. A., "Is Public Expenditure Productive?" Journal of Monetary Economics, 23, 1989, pp. 177-200.

[7] Batten, D. F., and Karlsson, C., "Infrastructure and the Complexity of Economic Development," Springer-Verlag, 1996.

[8] Aschauer, D. A., "Highway capacity and economic growth," Economic Perspectives, Federal Reserve Bank of Chicago, 14(5), 1990, pp. 14-24.

[9] Lombard, P. C., Sinha, K. C., and Brown, D. J., "Investigation of the relationship between highway infrastructure and economic development in Indiana," Transportation Research Record 1359, 1992, pp. 76-81.

[10] Lu, W., "Public infrastructure and regional economic development: evidence from China," Pacific Economic Paper No. 258, Australian National University, Canberra, 1996.

[11] Munnel, A. H. and Cook, L. M., "How does public infrastructure affect regional economic performance?" New England Economic Review, 15(5), 1990, pp. 11-32.

[12] Canning, D., Fay, M., and Perotti, R., "Infrastructure and growth," International differences in growth rates: market globalization and economic areas, Macmillan Press Ltd., New York, 1994, pp. 113-147.

[13] Man, J. Y., "Transportation infrastructure and regional economic development in China," International Journal of Public Administration, 21(9), 1998, pp. 1307-1321.

[14] Mohamad, D., "The relationships between road infrastructure investment and economic development," Proceedings of an International Conference on Transportation into the next Millenium, Nanyang Technological University, Singapore, 1998, pp.261-270.

[15] Vickerman, R. W., "Infrastructure and regional development," Pion Limited, London, 1991.

[16] Liu, C., and Itoh, Y., "Modeling Transportation Infrastructure and Economic Growth with Panel Data: A Case Study on Guangdong Province of China." The 7th East Asia-Pacific Conference on Structural Engineering \& Construction, Kochi, Japan, 1999.

[17] Guangdong Statistical Yearbook, China Statistical Publishing House, 1997 (in Chinese). 